Mindfulness and Counseling Self-Efficacy: The Mediating Role of Attention and Empathy

By: Paige Beniley Greason \& Craig S. Cashwell

Greason, P. B., \& Cashwell, C. S. (2009). Mindfulness and Counseling Self-Efficacy:

The Mediating Role of Attention and Empathy. Counselor Education and Supervision, 49, 2-19.

Made available courtesy of The American Counseling Association: http://www.counseling.org/

$* * *$ Reprinted from (Counselor Education and Supervision, 49, 2009) 2-19. (C) (2009) The American
Counseling Association. Reprinted with permission. No further reproduction authorized with out written
permission from the American Counseling Association.***

Abstract:

This study examined the predictive relationship between mindfulness and counseling, self-efficacy and the potential mediating effects of attention and empathy. Master's-level counseling interns and doctoral counseling students $(N=179)$ were surveyed to determine levels of mindfulness. attention. empathy. and counseling selfefficacy. Pearson product-moment correlation coefficients revealed significant pairwise relationships between the 4 variables of interest. A multiple-mediator path analysis supported the hypotheses that mindfulness is a significant predictor of counseling self-efficacy and that attention is a mediator of that relationship, Results suggest that mindfulness may be an important variable in the development of key counselor

preparation outcomes.

\title{
Article:
}

Among the skills considered essential to being an effective counselor are strategically controlling attention during the session and having both a cognitive and affective empathic response to the client (Lambert \& Barley. 2001; Orlinsky, Grave, \& Parks. 1994; Rogers. 1957. 1975: Wampold, 2001: Watson. 2001). A review of the literature reveals, however, that counselor educators have little empirically based direction on how to cultivate the internal habits of mind necessary for controlling attention and for having a multidimensional (i.e.. cognitive and affective) empathic response. Instead, the majority of training literature focuses on developing those empathic responses that are external and observable, such as mirroring and reflection of feeling. Moreover, some researchers suggest that counselor education programs leave much cognitive skill development to chance (Etringer \& Hillerbrand. 1995; Fong. Borders, Ethington. \& Pitts. 1997) and that this inattention to the cultivation of internal skills may result in decreased counseling self-efficacy, increased anxiety, decreased counseling performance, and decreased ability to learn new skills (Bandura. 1986: Larson \& Daniels. 1998). it has been theorized that mindfulness practice may help in the cultivation of key counseling skills, but researchers have done little to explore these relationships. Therefore, an investigation is warranted of mindfulness and the counselor skills and attributes of counseling self-efficacy, attention, and empathy.

\section{Counseling Self-Efficacy}

Counseling self-efficacy is defined as "one's beliefs or judgments about his or her capabilities to effectively counsel a client in the near future" (Larson \& Daniels, 1998, p. 180). According to theory, counseling selfefficacy is a primary mechanism between simply knowing how to help in a counseling situation and actually executing effective counseling actions. Although self-efficacy is not equivalent to competence (e.g., someone may think that he or she has the skills to counsel effectively but. in fact, may lack those skills), higher counseling self-efficacy is related to higher performance attainment because it increases motivation to complete a task (Bandura, f 986). In their review of the counseling self-efficacy literature, Larson and Daniels found that higher counseling self-efficacy is related to perseverance in the face of challenging counseling tasks and an increased ability to receive and incorporate evaluative feedback. They also found that counselors with strong counseling self-efficacy report less anxiety and interpret the anxiety they do have as challenging rather than as overwhelming or hindering. 
Many authors have asserted that cultivating self-efficacy in counselors is an important component of counselor development (Bischoff, 1997: Duryee, Brymer, \& Gold, 1996: Leach, Stoltenberg, McNeill, \& Eichenfield, 1997; Skovholt \& Ronnestad, 1992; Stoltenberg \& Delworth, 1987). Increasing self-efficacy is theorized to occur through four primary sources: (a) mastery experiences, (b) vicarious learning, (c) verbal persuasion, and (d) changes in emotional arousal (Bandura, 1986). Mastery experiences, in which individuals have personal experience with learning a skill, are considered to be the most powerful means of developing a sense of efficacy. For counselor educators, this means that offering students mastery experiences in the core counseling skills is crucial to developing counseling self-efficacy.

Outcome research reveals that two essential skills for successful counseling are the capacity to maintain attentive presence and the ability to empathize with the client (Lambert \& Barley, 2001; Orlinsky et al., 1994; Wampold, 2001; Watson, 2001). Etringer and Hillerbrand (1995) pointed out that counseling experts can both direct their attention more efficiently and monitor their own cognitions more than can counseling novices. Similarly, O'Byrne, Clark, and Malakuti (1997) stated that advanced counselors are skilled in focusing their attention strategically. When the counselor is unable to sustain attention, the session may be characterized by a lack of intimacy, remoteness, and detachment (Truax \& Carkhuff, 1967). Accordingly, 98\% of surveyed counselor educators at programs accredited by the Council for Accreditation of Counseling and Related Educational Programs (CACREP) expected that, by the end of their practicum experience, students should be proficient in attending and empathy skills (Bradley \& Fiorini, 1999).

\section{Attention}

Because it is related to a variety of cognitive processes (e.g., perception, memory. planning, speech), attention is a difficult construct to define. Neuropsychologists consider attention to be a system of cognitive subprocesses rather than a single function, yet a full understanding of how these subprocesses operate is still unknown (Gopher. 1993; Leclercq, 2002; Zimmerman \& Leclercq, 2002). It is suggested that the process of paying attention includes four primary mental capacities: selective attention (i.e.. the ability to attend to some aspect of experience while ignoring others), divided attention (i.e., the ability to simultaneously hold attention on two different objects or tasks), sustained attention (i.e., the ability to hold attention over some period of time), and attention switching (i.e., the ability to change focus from one object to another). The literature further suggests that the four capacities are interrelated. The ability to divide attention seems to be regulated by the ability to switch attention from one object to another (attention switching), and the ability to sustain attention may be regulated by the ability to avoid distractions (selective attention). For the purposes of this study, the ability to strategically control attention in the counseling session is defined as the ability to sustain and divide attention.

Although everyone has the capacity for attention, individuals differ in their ability and propensity to sustain attention and control its focus. In a counseling session, for instance, a counselor may become easily distracted by internal dialogue or, conversely, may focus almost exclusively on the content of the client's narrative, overlooking the process. With practice, however, these skills can be improved (Brown \& Ryan, 2003; KabatZinn, 2003: Leclercq, 2002). Because strategically controlling attention is essential to the counseling process, counseling students need mastery experiences in attention skills to hone this important mental skill. Although other professions (e.g., medicine, sports) are beginning to recognize the value of attention training (R. M. Epstein. 2003; Gill. 2000), actual training in cultivating core attention capacities seems to be missing from counselor education.

\section{Empathy}

Models for empathy development in counselor education emphasize training in the external, observable communication of empathy (e.g., Ivey \& Ivey, 2003) rather than the internal mental processes that lead to empathic communication. Literature on empathy defines it as a multidimensional process that first involves an affective response (e.g., a gut feeling of anxiety) that leads to a cognitive response (e.g., reflecting feeling: Bohart \& Greenberg, f997: Duan \& Hill. 1996: Feshbach, 1975: Hoffman. 1975). Being able to be empathic also requires an ability to suspend judgment and bias to walk in the other's shoes. To suspend judgment and 
understand the client's world, the counselor must be able to tolerate a client's difficult feelings and the difficult feelings that may arise in the counselor - rather than avoiding them or overidentifying with them (e.g., crying in the session). This ability is often referred to as having affect tolerance (Fulton, 2005; Goldstein \& Michaels, 1985 Morgan \& Morgan, 2005).

Although current training models in counselor education may help students to identify feelings, to communicate those feelings specifically and concretely, and to act as if they are empathic, they may not necessarily offer students the affective experience of empathy considered necessary for the development of genuine empathy. Furthermore, although counselor education research and literature encourage exploration of personal values and biases, specific instruction on how to suspend the human tendency to judge and evaluate experience is lacking. The expectation seems to be that the ability to engage empathically with clients will naturally develop from accurately identifying and communicating client feelings.

The focus on external, observable counseling skills rather than on the internal processes of attention and empathy results in a gap between theory and practice in counselor education that may have a profound impact on counselor development and counseling outcomes. A number of theorists have suggested that mindfulness training may be an important tool to bridge this gap (Bien, 2006; Block-Lerner, Adair, Plumb, Rhatigan, \& Orsillo. 2007; Fulton, 2005; Germer. 2005; Martin, 1997; Morgan \& Morgan, 2005; Schure, Christopher. \& Christopher, 2008; Walsh \& Shapiro. 2006).

\section{Mindfulness}

The seminal definition of mindfulness is "paying attention in a particular way: on purpose, in the present moment, and nonjudgmentally" (Kabat-Zinn, 1994, p. 4). Shapiro, Carlson, Astin, and Freedman (2006) identified three interconnected "building blocks" (p. 375) of mindfulness: intention, attention, and attitude. Mindfulness is thus a state of being attentive to experience that is characterized by an attitude of openness and acceptance of experience (Brown \& Ryan, 2003; Kabat-Zinn, 2003; Martin. 1997). In many ways, it mirrors Freud's (as cited in M, Epstein, 1995) concept of "evenly suspended attention" (p. 114: i.e.. attending to the client without having preconceived ideas or biases), which Freud considered a central component of therapy.

For thousands of years, spiritual seekers have used mindfulness techniques to help train the mind to concentrate and remain non-judgmentally focused on the present moment and to increase affect tolerance (i.e., the ability to tolerate difficult feelings in the self or others) - all skills that are important for counselors. Several reviews of the mindfulness literature reveal that researchers and clinicians are effectively applying the techniques of mindfulness to the treatment of a variety of physical and mental health issues with significant results (Baer, 2003: Bishop, 2002; Grossman, Niemann. Schmidt, \& Walach, 2004: Lazar, 2005), Moreover, research findings support the proposed relationship between mindfulness and the ability to strategically control attention (Bögels. Sijbers, \& Voncken, 2006; Shapiro, Brown, \& Biegel, 2007: Valentine \& Sweet, 1999) as well as the relationship between mindfulness and empathy (Bead, Ferrer, \& Cecero. 2004: Schure et al., 2008: Shapiro, Schwartz, \& Bonner, 1998).

Valentine and Sweet (1999) found that practitioners of mindfulness meditation scored significantly higher on a test of sustained attention compared with a control group. Bagels et al. (2006) found that mindfulness training helped individuals with social phobia reduce self-focused attention and increase task-focused attention. in their study with master's-level counseling psychology students, Shapiro et al. (2007) found that mindfulness-based stress reduction training resulted in a reduction in ruminative attention. Beitel et al. (2004) found that mindfulness was significantly correlated with empathic concern (i.e., the ability to have an affective response to the experiences of another) and perspective taking in undergraduate students. Similarly, Shapiro et al. (1998) found significant increases in empathy in a treatment group of medical students when compared with a control group. Furthermore, in their qualitative study of counseling students, Schure et al. (2008) found that participants in a 15-week course in mindfulness reported substantial effects on their counseling skills, including enhanced listening skills and empathy. A review of the literature, however, reveals a lack of quantitative studies about mindfulness in counselor preparation. 


\section{Purpose of the Study}

The purpose of this exploratory study was to address an important gap in the counselor education literature by investigating the relationships between mindfulness, attention, empathy, and counseling self-efficacy in counselors-in-training. We examined a path model that hypothesized a predictive relationship between mindfulness and counseling self-efficacy mediated by attention and empathy. Per path analysis protocol, we also hypothesized a relationship between mindfulness and the two mediator variables (i.e., attention and empathy), as well as a relationship between the two mediator variables and counseling self-efficacy. The following research questions were addressed in our sample of counselors-in-training:

Research Question 1: What are the relationships between mean scores of mindfulness, attention, empathy, and counseling self-efficacy?

Research Question 2: What are the relationships between mindfulness, attention, empathy, and counseling selfefficacy within a path model that specifies a relationship between mindfulness skills and counseling selfefficacy mediated by attention and empathy?

\section{Method}

\section{Participants}

Master's-level counseling interns who had completed at least one semester of internship at CACREP-accredited programs that required at least a two-semester internship participated in the study. Doctoral students from CACREP-accredited programs were also recruited as participants to obtain a greater range of counseling experience (it was assumed that all participating doctoral students had completed a master's-level internship). Participants were recruited by contacting counselor educators who work with master's-level interns and doctoral students and obtaining their agreement to distribute instrument packets at the end of class or supervision.

A total of 421 instrument packets were sent by postal mail to 15 schools, of which 8 had both a master's-degree program and a doctoral program. A total of 187 packets were returned from 10 schools for a return rate of $44 \%$. Five of the 10 schools offered both master's and doctoral degrees. Eight surveys were removed from the data set because they were incomplete, leaving a total of 179 participants. Of the 179 participants, 129 (72.10101 were master's interns and 50 (27.9\%) were doctoral students. The master's-level students reported having earned an average of 45.13 graduate credit hours in counseling-related courses: doctoral students reported having earned an average of 84.90 hours. In addition, $153(85.5 \%)$ participants were female, and $26(14.5 \%)$ were male. The average age was 29.86 years $(S D=6.94)$. The majority of participants identified as Caucasian $(n=142,79.3 \%)$. A small percentage indicated ethnic minority status, primarily African American $(r=20.11 .2 \%)$. Other identified races/ethnicities were Asian $(n=4.2 .2 \%)$. Asian American $(n=2,1.1 \%)$, Hispanic/Latino $(n=4$. $2.2 \%$ ). and multiracial ( $n$ 7. 3.9\%). (Percentages do not equal 100\% because of rounding.)

\section{Instruments}

Five Factor Mindfulness Questionnaire (FFMQ: Baer; Smith. Hopkins. Krietemeyer \& Toney, 2006). The FFMQ is a synthesis of several recently developed mindfulness questionnaires, including the Mindful Attention Awareness Scale (Brown \& Ryan. 2003), the Freiburg Mindfulness Inventory (Buchheld, Grossman, \& Walach, 2001), and the Kentucky Inventory of Mindfulness Skills (Baer, Smith, \& Allen, 2004). Consequently, the FFMQ represents the collective understanding among scholars of what mindfulness is and how it should be operationalized. Baer et at. (2006) found that the five mindfulness questionnaires that informed the FFMQ all demonstrated good internal consistency (.81-.87) and were correlated with one another and with meditation experience as expected. With one exception, convergent and discriminant correlations were in the expected directions. Baer et al. (2006) also conducted exploratory and confirmatory factor analyses with a combined item pool from all live questionnaires, yielding a clear five-factor model.

The 39-item FFMQ measures five factors of mindfulness: Observing, Describing. Acting With Awareness, and Nonjudging. The five factors form a total mindfulness score, which reflects a global measure of mindfulness. 
The total score was used as the unit of analysis in this study. The FFMQ uses a 5-point Likert-type scale ranging from 1 (never or very rarely true) to 5 (very often or always true). Internal consistency factor coefficients range from .75 to .91, and Baer et al. (2006) reported an estimate of reliability of .96 for the total instrument, with interfactor correlations ranging from .15 to .34. In the current study, the total reliability was .88 .

Counselor Attention Scale (CAS: Greason, 2006). After an extensive review of the literature, we found no paper-and-pencil instruments to measure counselors' ability to strategically control their attention during counseling sessions. Therefore, to accurately measure the attention capacities of counselors (i.e., divided attention and sustained attention), the first author developed the CAS.

The original 14-item CAS was reviewed by an expert panel that included three doctoral-level counselor educators and two full-time practicing counselors with a combined total of 87 years in the field. On the basis of this expert review, the items seemed to have strong face validity. The CAS was administered to 31 master'slevel counseling students with internship experience on two separate occasions, 2 weeks apart. Test-retest reliability of the CAS ( $n=30$ ) was .80 . A form was included in the administration for participants to provide feedback on item clarity.

On the basis of the results of the pilot study, the CAS was modified to better discriminate between individuals with high and low attention and between the two attention capacities themselves. High capacity for sustained attention is defined as being able to maintain attention on an important aspect of the session. It includes such abilities as not being distracted by irrelevant stimuli and not missing any aspect of the client's narrative. Low capacity for sustained attention includes such things as an inability to summarize the client's narrative because of missing key elements and trying to pay attention to too many things at once. For divided attention, high capacity is defined as the ability to direct attention to more than one thing at a time in the session. It includes such things as directing attention both internally and externally and awareness of discrepancies between client narrative and nonverbals. Low capacity includes such things as losing important information because of being exclusively focused on something else. The final version of the CAS contains 22 questions and is divided into two sections. Section 1 measures level of difficulty for each item, with response options ranging from 1 (very difficult) to 5 (very easy). Section 2 measures frequency for each item, and response options range from 1 (occurs at least once in most all sessions) to 5 (never occurs). The questions are specific to attention in the counseling session (e.g.. When my client talks to me, I find myself distracted by my own thoughts and ideas"). The reliability alpha of the CAS for this study was .88.

Interpersonal Reactivity Index (IRI; Davis. 1980, 1996), The IRI is designed to assess multidimensional empathy in social situations. It is the most widely researched and comprehensive multidimensional assessment of empathy available (Cliffordson. 2002). The Barrett-Lennard Relationship Inventory (Barrett-Lennard. 1978) is the instrument often used in counseling research. This instrument, however, assesses only the cognitive aspects of empathy (Duan \& Hill. 1996). Because the current study defined empathy as a multidimensional process, the IRI was selected because it assesses both cognitive and affective aspects of empathy.

The MI is a 28-item self-report measure with responses ranging from 1 (does not describe me) to 5 (describes me well). The IRI consists of four subscales, each tapping different aspects of empathy: Perspective Taking, Empathic Concern, Fantasy, and Personal Distress. Researchers have found internal consistency reliabilities of the four subscales that range from .70 to .82 (Davis. 1980: Pulps. Elison. \& Lennon, 2004). Test-retest reliabilities range from .62 to .71 over a 2-month period (Davis, 1980). Davis (1980) considered the Perspective Taking and Empathic Concern subscales to reflect the most advanced levels of empathy. The Perspective Taking subscale is designed to measure cognitive empathy, and the Empathic Concern subscale is designed to measure affective empathy, The Personal Distress and Fantasy subscales represent lower and intermediate levels of empathy, respectively. In fact. Davis (1980) advised that the Personal Distress subscale correlates negatively with the other subscales and indicates susceptibility on the part of the listener to overidentify with 
the difficult emotions of the other person, Because the Perspective Taking and Empathic Concern subscales are the most representative of multidimensional empathy in mature adults, these two subscales were combined for a total empathy score in the current study. These combined subscales represent 14 of the total 28 items on the IRI, although participants in the current study completed the entire 28 -item questionnaire. The composite estimate of reliability for the IRI total score in our sample was .96 .

Counselor Activity Self-Efficacy Scales (CASES: Lent, HIM \& Hoffman, 2003). The CASES is designed to assess counseling self-efficacy in three general areas: performing general helping skills (Exploration Skills), managing the counseling process (Session Management), and handling challenging counseling situations (Client Distress). The total score of all three general areas reflects overall counseling self-efficacy. This instrument was designed to address criticisms of earlier measures of counseling self-efficacy (e.g., Counseling Self-Estimate inventory: Larson et al.. 1992), specifically that those instruments assume knowledge beyond the level of new counselors-in-training. measure constructs other than self-efficacy (e.g.. values), do riot measure more advanced skills or role requirements, and are not grounded in counselor development theory (Lent, Hackett, \& Brown, 1998: Lent et al.. 2003). The CASES was developed to address these criticisms and provide an expanded understanding of counseling self-efficacy.

The CASES contains 31 questions, and participants answer how confident they are in their abilities to perform various tasks with most clients in the next week. Respondents rate each item on a 10-point Likert-type scale ranging from 0 (no confidence at all) to 9 (complete confidence). Reliability estimates for the individual subscales in previous research range from .79 (Exploration Skills) to .94 (Session Management and Client Distress). Lent et al. (2003) reported an estimate of reliability of .97 for overall counseling self-efficacy. The CASES total score was used in the current study, and the estimate of reliability for overall counseling sellefficacy was .96 .

Demographic questionnaire. Participants were asked to provide information about their age, gender, race/ethnicity, level of training (i.e., currently enrolled in a master's or doctoral degree program), and number of completed graduate-level counseling credit hours.

\section{Procedure}

Following institutional review board approval, counselor educators were asked to distribute the informed consent forms and instrument packets after class or supervision to master's-level students who had completed at least one semester of internship and to any doctoral-level students in their programs. Participation in this study was strictly voluntary, and no incentives were offered. Potential participants were told that the study would examine the relationships between mindfulness, attention, empathy, and counseling self-efficacy. Participants were informed that completion of the instrument packet would take approximately 20 to 25 minutes and that their identities and responses would be anonymous. Instrument packets and informed consent forms were mailed back to us in self-addressed stamped envelopes, which we provided.

\section{Data Analysis}

To test the multiple-mediator hypotheses that attention and empathy mediated the relationship between mindfulness and counseling self-efficacy, we conducted a path analysis according to causal steps criteria originally outlined by Baron and Kenny (1986). Path analysis uses standard regression techniques to explore the predictive relationships between variables. Using this method, one must meet three requirements for mediation. First, as in single-mediator mediation, the total effect (c path) from the independent variable (i.e.. mindfulness) to the dependent variable (Le., counseling self-efficacy) must be significant. Second, the direct paths ( $a$ paths) from the independent variable (i.e., mindfulness) to the mediators (i.e., attention and empathy) must be significant. Finally, the mediators must be significant predictors of the dependent variable ( $b$ paths) when both the independent variable and the mediators are entered into the regression model simultaneously to predict the dependent variable. The direct effect ( $c^{1}$ path) is the effect or the independent variable on the dependent variable and is found by entering the independent variable and the mediators into the regression model simultaneously, if the effect of the independent variable on the dependent variable is no longer significant when adding the 
mediators to the regression analysis, the effect of the independent variable on the dependent variable is considered completely mediated (Le.. lull mediation). Full mediation means that changes in the independent variable lead to changes in the mediating variables, which in turn lead to changes in the dependent variable. If the direct effect is significant but is smaller than the total effect ( $c$ path), evidence of partial mediation can be claimed, meaning some of the effect of the independent variable on the dependent variable can be explained by the effect of the independent variable on the mediator, but not all.

Researchers have criticized the causal steps method because it does not directly address the indirect effect (i.e., meditation), which is the question of interest (Preacher 8z Hayes, 2008). A point estimate of the indirect effect of the independent variable on the dependent variable through the mediators can be calculated using causal steps as the product of the unstandardized regression weights for the $a$ and $b$ paths. Nevertheless, the statistical significance of this point estimate is not available. An alternative strategy, the product of coefficients (i.e., Sobel's z test), does test whether the indirect effect is significantly different from zero. Preacher and Hayes suggested, however, that this method assumes multivariate normal distribution of the sample, which is rare with smaller samples. They suggested using the bootstrapping method instead. This method statistically generates a nominal sample distribution of point estimates of the indirect effect. Bootstrapping creates a normal curve distribution by reestimating $a$ and $b$ and then $a b$ at least 1,000 times. When this method is used, mediation occurs if the confidence interval for the indirect effect point estimate does not contain zero Therefore, in addition to the causal steps method, we calculated the bootstrapping point estimates of the indirect effects and 95\% confidence intervals for those estimates using a macro created by Preacher and Hayes (2008) for the SPSS (Version 15.0) statistics program.

\section{Results}

We conducted a preliminary examination of the relationships between mean scores of the FFMQ. the CAS, the IRI, and the CASES. As hypothesized, Pearson product-moment correlations between pairwise mean scores were all statistically significant at $p=.01$ (see Table 1$)$.

The model hypothesized that mindfulness would be a significant predictor of counseling self-efficacy when attention and empathy were entered in the model as mediators. Table 2 presents the results of the path analysis, and Table 3 provides a comparison of the causal steps and bootstrapping methods. Figure 1 provides a visual display of the path model. Mindfulness, as measured by the FFMQ, significantly predicted attention, as measured by the CAS ( $a^{1}$ path) at $\beta=.53$ and accounted for $28 \%$ of the variance in CAS mean scores (adjusted $\left.R^{2}=.28, t=8.41, p<.01\right)$. FFMQ scores also significantly predicted empathy, as measured by the IRI $\left(a^{2}\right.$ path $)$ at $\beta=.27$ and accounted for $7 \%$ of the variance in IRI mean scores (adjusted $R^{2}=.07, t=3.77, p<.01$ ). As hypothesized, when entered into the model as the sole predictor, FFMQ mean scores significantly predicted counseling self-efficacy, as measured by the CASES ( $c$ path) at $\beta=.34$ and accounted for $11 \%$ of the variance in CASES mean scores (adjusted $R^{2}=.11, t=4.88, p<.01$ ). To test for mediation, we entered mean scores on the FFMQ, the CAS, and the IRI into a regression model to predict CASES scores. The resulting $c^{1}$ path was not significant at $\beta=.03(t=0.37, p=.71)$, demonstrating full mediation of the relationship between FFMQ mean scores and CASES mean scores by CAS and IRI mean scores (Baron \& Kenny. 1986). The adjusted $R^{2}$ of this full model was .34.suggesting that FFMQ, CAS, and IRI mean scores account for $34 \%$ of the variance in CASES mean scores $(F=32.11, p<.01)$.

An examination of the direct and indirect effects of the proposed mediators revealed that attention (as measured by the CAS) was a statistically significant mediator but empathy (as measured by the IRI) was not. Per Baron and Kenny's (1986) requirements for mediation, the CAS was a statistically significant predictor of the CASES $\left(\mathrm{b}^{1}\right.$ path) when entered with FFMQ and IRI mean scores into the regression model $(\beta=.56, t=7.76, p<.01)$. IRI mean scores, on the other hand, did not have a statistically significant direct effect on CASES mean scores ( $b^{2}$ path: $\beta=.06, t=0.95, p=.35$ ). Bootstrapping analyses of indirect effects of the paths between the CAS and the CASES as well as between the IRI and CASES confirmed that the IRI was not a mediator of the relationship between FFMQ and CASES mean scores. 
TABLE 1

Pearson Product-Moment Correlations and Reliability Coefficients for the Four Variables Under Study

\begin{tabular}{lcccc}
\hline \hline Variable & 1 & 2 & 3 & 4 \\
\hline 1. FFMQ & .88 & - & & \\
2. CAS & $.53^{*}$ & .88 & - & - \\
3. IRI & $.27^{*}$ & $.25^{*}$ & .84 & .96 \\
4. CASES & $.34^{*}$ & $.59^{*}$ & $.21^{*}$ & \\
\hline
\end{tabular}

Note. Reliability coefficients are on the diagonal. FFMQ = Five Factor Mindfulness Questionnaire; $\mathrm{CAS}=$ Counselor Attention Scale; IRI = Interpersonal Reactivity Index; CASES = Counselor Activity Self-Efficacy Scales.

${ }^{*} p<.01$, two-tailed.

\section{TABLE 2}

\section{Path Analysis of Relationships Between Mindfulness, Attention, Empathy, and Counseling Self-Efficacy $(N=179)$}

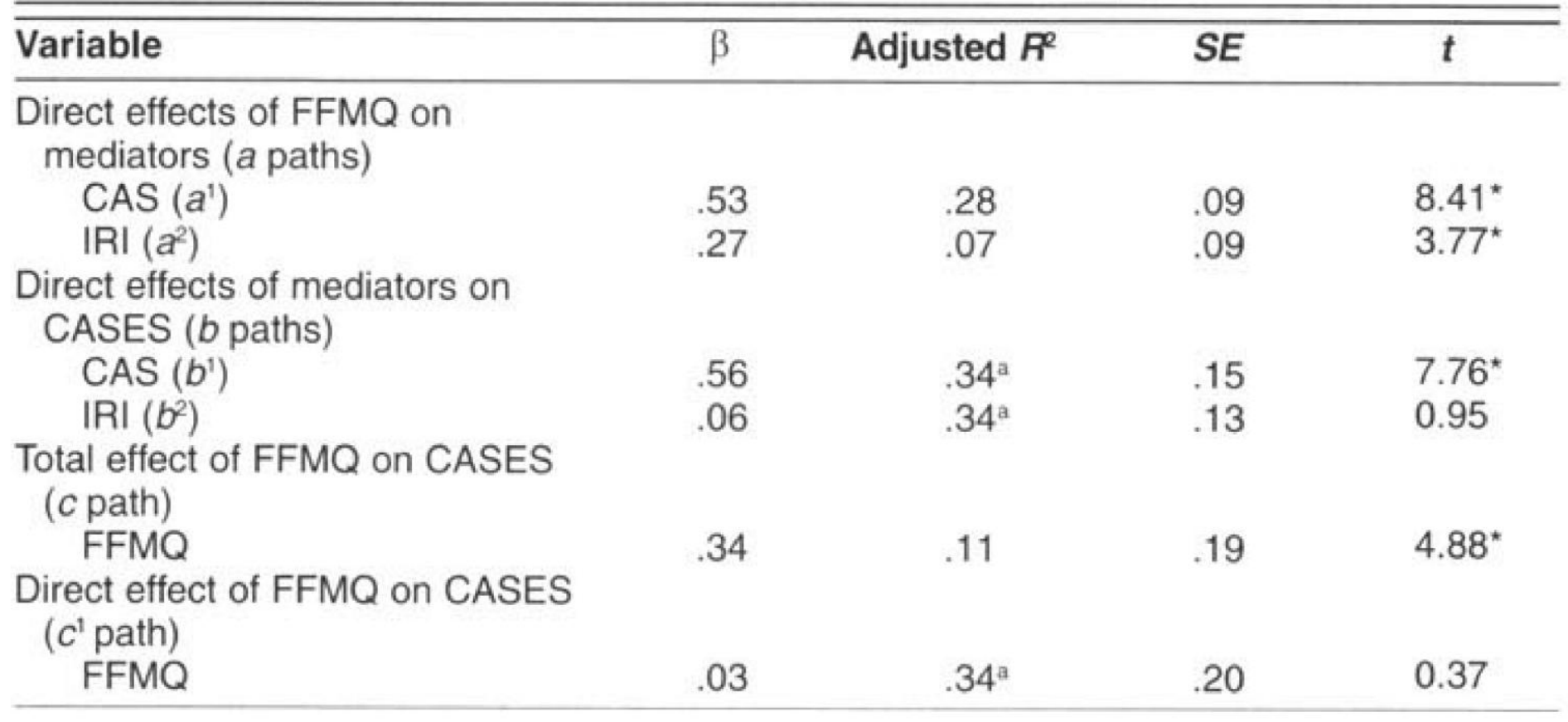

Note. FFMQ = Five Factor Mindfulness Questionnaire; CAS = Counselor Attention Scale; IRI = Interpersonal Reactivity Index; CASES = Counselor Activity Self-Efficacy Scales.

${ }^{\mathrm{a}} F(3,175)=32.11, p<.01$.

${ }^{*} p<.01$. 
TABLE 3

\section{Comparison of Causal Steps and Bootstrapping Point Estimates and Confidence Intervals (Cls) for Indirect Effects}

\begin{tabular}{|c|c|c|c|c|c|}
\hline \multirow[b]{3}{*}{ Variable } & \multirow{3}{*}{$\begin{array}{c}\text { Causal Steps } \\
\text { ab Path Point } \\
\text { Estimate }\end{array}$} & \multicolumn{4}{|c|}{ Bootstrapping } \\
\hline & & \multirow{2}{*}{$\begin{array}{l}a b \text { Path Point } \\
\text { Estimate }\end{array}$} & \multicolumn{2}{|c|}{ Bias-Corrected $95 \% \mathrm{Cl}$} & \multirow[b]{2}{*}{ Mediation } \\
\hline & & & Lower & Upper & \\
\hline CAS & .80 & .81 & 0.57 & 1.09 & Yes \\
\hline |RI & .05 & .04 & -0.03 & 0.17 & No \\
\hline
\end{tabular}

Note . CAS $=$ Counselor Attention Scale; $\mid \mathrm{RI}=$ Interpersonal Reactivity Index.

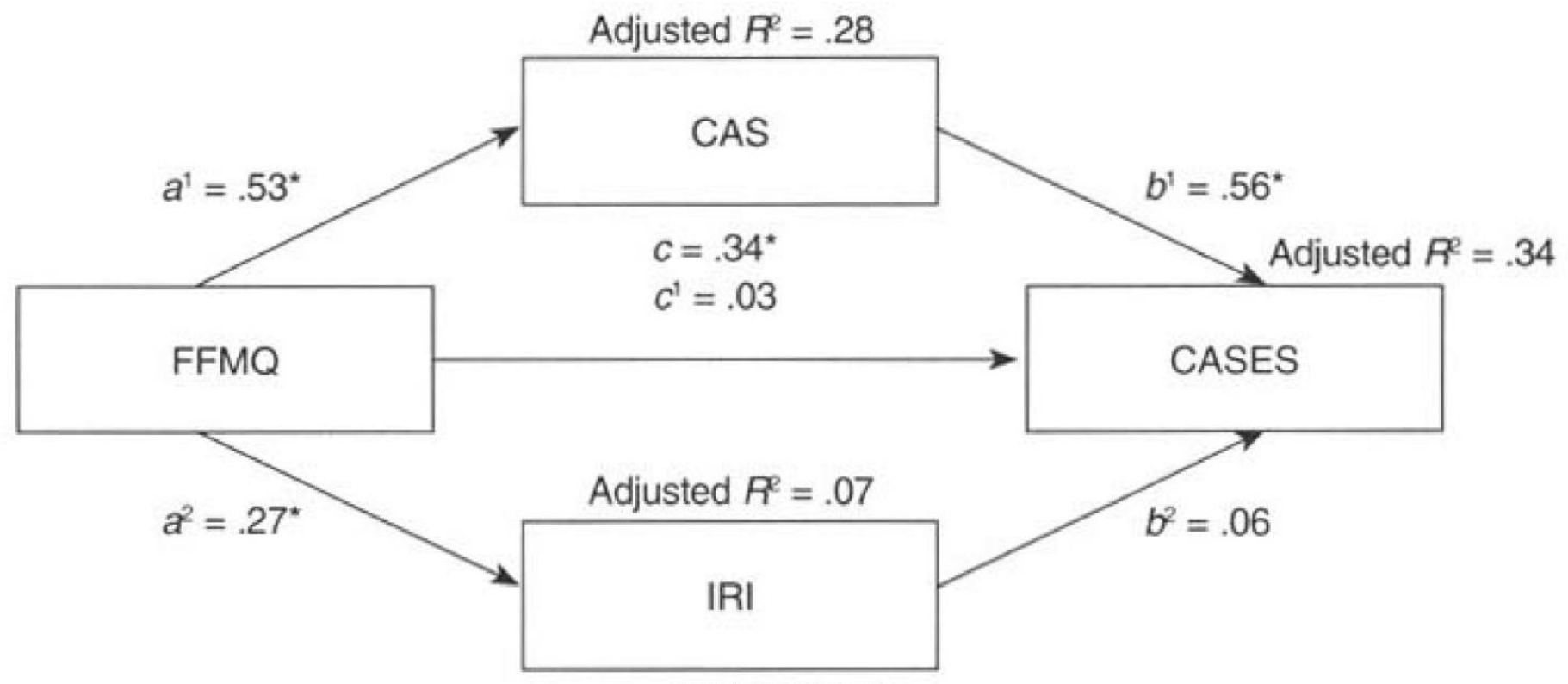

FIGURE 1

\section{Path Analysis Depicting Direct and Total Effects and Adjusted $R^{R}$}

Note . CAS = Counselor Attention Scale; FFMQ = Five Factor Mindfulness Questionnaire; CASES = Counselor Activity Self-Efficacy Scales; $\mid \mathrm{RI}=$ Interpersonal Reactivity Index; $a$ paths = direct effects of FFMQ on mediating variables; $b$ paths = direct effects of mediating variables on CASES; $c$ path $=$ total effect of FFMQ on CASES; $c^{1}$ path $=$ direct effect of FFMQ on CASES.

${ }^{*} p<.01$.

\section{Discussion}

This study provides empirical support for the theorized relationship between mindfulness and key counselor preparation and development outcomes. The results support the hypothesis that mindfulness is a predictor of counseling self-efficacy in master's-level and doctoral-level counseling students. Our study found that attention was a mediator of that relationship. Although empathy did not predict counseling self-efficacy as hypothesized and was not a mediator, mindfulness did significantly predict empathy. 
Initial, correlations between the four variables of interest - mindfulness, attention, empathy, and counseling self-efficacy - showed that the four variables in the study were significantly related to one another. There were no extreme correlations, however, between predictor variables, suggesting that multicollinearity was not an issue (Mansfield \& Helms, 1982). These findings support previous research that mindfulness is related to attention (Bögels et al., 2006: Shapiro et al., 2007: Valentine \& Sweet, 1999) and empathy (Beitel et al., 2004; Schure et al., 2008: Shapiro et al., 1998) and suggest that further exploration of the predictive nature of mindfulness, attention, and empathy on counseling self-efficacy is warranted.

Our study provides evidence that a sizable portion of the variance in counseling self-efficacy (34\%) can be explained by a counselor's ability to be mindful, to be empathic. and to strategically control attention in the counseling session. Students who can be mindful in everyday life are more likely to strategically control their attention in the counseling session and to be empathic. They can sustain nonjudgmental attention on the client's narrative as well as divide attention to observe such things as client nonverbals without getting lost in their own inner dialogue.

One explanation for these findings is that increased mindfulness shifts the orientation from a doing mode to a being mode because the attentional focus of mindfulness is on accepting and allowing rather than trying to change current experience (Bo el et al., 2006). The predictive relationship between mindfulness and attention in the counseling students in our study may indicate differences in the ability to be rather than to do and an increased ability to tolerate difficult feelings. Students who are more mindful would be able to accept current experience without reacting to it or judging it and, therefore, would be more likely to remain focused on the present moment in the counseling session rather than getting lost in cognitive exploration of what to do or how to fix the problem. For example, a more mindful student would be able to nonjudgmentally accept that a woman dealing with an abusive partner may have ambivalent feelings about leaving that partner. The counselor would be able to stay present, fully hear the client's story, and engage empathically. The less mindful student, on the other hand, may judge the woman's emotions as "wrong" or bad." This counselor's attentional focus may shift from being present with the client to trying to think of ways to fix the client's situation. Our findings suggest that mindfulness may be an important tool not only for cultivating attentional capacities in counseling students, but also for helping students learn to be with clients.

Although our study demonstrated a significant predictive relationship between mindfulness and empathy, an unexpected finding was the nonsignificant predictive weight of empathy on counseling self-efficacy. These particular findings may reflect measurement issues. Although the CAS assessed attention ability in the counseling session, the IRI was not counseling specific. Rather, it assessed cognitive and affective empathic responses in everyday life. Some scholars have suggested that empathy in the counseling relationship may be different from empathy in social settings because it requires a communication of understanding to the other person (Barrett-Lennard. 1981; Keefe, 1976: Rogers, 1975). Therefore, the manner in which counseling students respond in the counseling session may differ from how they respond to people in general. Other researchers who have used the II with health care professionals suggested that nonsignificant effects may be due to scale sensitivity (Galantino, Baime. Maguire. Szapary, \& Farrar, 2005).

On the basis of these exploratory findings, mindfulness training may be an important tool for cultivating the internal skills that are fundamental to the counseling relationship, Additional empirical inquiry, however, is needed.

\section{Implications for Counselor Preparation and Further Research}

Results of this study should be examined within the context of study limitations, including those inherent to survey research, such as differences between persons who chose to participate and those who declined, selfreport limitations, and social desirability bias. A confounding variable may be the instruction-or lack of instruction - participants received in their counseling classes on such things as mindfulness, the role of affective empathy in the counseling process, strategic attention control in session, and the effects of mental practice techniques. Because the CAS was developed specifically for this study, and construct validity of attention in the counseling session has yet to be determined, results should be interpreted with caution. A convenience sample 
was used in the study, limiting generalizability. Participants were from CACREP-accredited counseling programs primarily located in the southeastern part of the United States. The results may not generalize to those students in non-CACREP schools or in other geographical areas.

Despite these limitations, our findings have important implications for counselor educators and supervisors. Counselor educators and supervisors should consider incorporating mastery-based experiences in the five core mindfulness skills (i.e., observing, describing, nonjudging, nonreacting, and acting with awareness) outlined by Baer et al. (2006) into counselor preparation curriculum and counselor supervision as a way to develop attention and empathy skills. These experiences could be infused into existing counselor education courses or through a course dedicated specifically to mindfulness training. Because these practices are often based on activities of daily living, training in mindfulness skills would add a mastery-based, skill-building technique that students could practice outside of class rather than simply in class or in session. Supervisors could include an assessment of mindfulness skills at the beginning stages of supervision and work with supervisees to develop skills that are lacking. it should be noted that scholars recommend that mindfulness instructors have their own practice (Kabat-Zinn. 2003: Segal, Williams, \& Teasdale, 2002). Therefore, to teach mindfulness skills, counselor educators and supervisors are advised to seek training in mindfulness and develop their own practice.

Replicating this study to include counselors with more experience (e.g., counseling practitioners and counselor supervisors) would shed light on the developmental component of mindfulness in counselors. An intervention study in which counselors-in-training receive specific training in mindfulness skills and changes in attention, empathy, and counseling self-efficacy would provide more causal data regarding the impact of mindfulness on. training outcomes. Future studies should also consider different forms of data collection beyond self-report. These would include ratings by supervisors or clients, behavioral observations, and performance assessments to reduce the likelihood of self-report bias. Furthermore, although the current measure of empathy was selected because it assesses multidimensional empathy, including a measure of clinical empathy rather than social empathy would strengthen how the relationship between mindfulness and empathy in the counseling session is understood.

Other researchers have linked mindfulness to a number of important outcome variables that were not examined in this study but that are relevant for counselors, counselor educators, and counselor supervisors. These variables include increased affect tolerance, self-compassion, psychological mindedness, and well-being and decreased anxiety. We recommend that future research include these important outcome variables. Ultimately, researchers should examine the critically important relationship between counselor mindfulness and client outcomes. If positive relationships are found between mindfulness in counselors and client outcomes, counselor educators would have an empirical foundation for inmindfulness into the counselor preparation curriculum.

\section{References}

Baer. R. A. (2003). Mindfulness training as a clinical intervention: A conceptual and empirical review. Clinical Psychology: Science and Practice, 10, 125-143.

Baer. R. A., Smith, G. T. \& Allen. K. B. (2004) Assessment of mindfulness by self-report: The Kentucky inventory of Mindfulness Skills. Assessment, 11, 191-206.

Baer. R. A., Smith. G. T., Hopkins. J., Krietemeyer. J., \& Toney. L. (2006). Using self-report assessment methods to explore facets of mindfulness. Assessment, 13. 27-45.

Bandura. A. (1986). Social foundations of thought and action: A social cognitive theory. Englewood Cliffs, NJ: Prentice Hall.

Baron. R, M., \& Kenny. D. A. (1986). The moderator-mediator variable distinction in social psychological research: Conceptual. strategic, and statistical considerations. Journal of Personality and Social Psychology. 51. 1173-1182.

Barrett-Lennard, G. T, (1978). The Relationship Inventory: Later development and, applications. JSAS Catalog of Selected Documents in Psychology, 8, 69, Manuscript No. 1732.

Barrett-Lennard, G. T. (198 IL The empathy cycle: Refinement of a nuclear concept, Journal of Counseling Psychology, 28, 91-100. 
Beitel, M., Ferrer, E., \& Cecero. J. J. [2004). Psychological mindedness and awareness of self and others. Journal of Clinical Psychology. 61, 739-750.

Bien, T. (2006). Mindful therapy: A guide for therapists and helping professionals. Somerville, MA: Wisdom.

Bischoff, R. J. (1997). Themes in therapist development during the first three months of clinical experience. Contemporary Family Therapy. 19. 563-580.

Bishop, S. R. (2002). What do we really know about mindfulness-based stress reduction? Psychosomatic Medicine. 64. 71-84.

Block-Lerner. J., Adair, C., Plumb, J. C., Rhatigan, D. L., \& Orsillo, S. M. (2007). The case for mindfulnessbased approaches in the cultivation of empathy: Does nonjudgmental, present-moment awareness increase capacity for perspective-taking and empathic concern? Journal of Marital and Family Therapy. 33. 501-516.

Bögels. S. M., Sijbers. G. F. V. M., \& Voncken. M. (2006). Mindfulness and task concentration training for social phobia: A pilot study. Journal of Cognitive Psychotherapy: An International Quarterly, 20, 3344.

Bohart, A., \& Greenberg, L. S. (1997). Empathy reconsidered. Washington, DC: American Psychological Association.

Bradley, C. \& Fiorini, J. (1999). Evaluation of counseling practicum: National study of programs accredited by CACREP. Counselor Education and Supervision. 39. 110-119.

Brown. K. W., \& Ryan. R. M. (2003). The benefits of being present: Mindfulness and its role in psychological well-being. Journal of Personality and Social Psychology, 84. 822-848.

Buchheld. N., Grossman, P., \& Walach. H. (2001). Measuring mindfulness in insight meditation (Vipassana) and meditation-based psychotherapy: The development of the Freiburg Mindfulness Inventory (FMC). Journal for Meditation and Meditation Research. 1, 11-34.

Cliffordson, C. (2002). The hierarchical structure of empathy: Dimensional organization and relations to social functioning. Scandinavian Journal of Psychology, 43, 49-59.

Davis, M. H. (1980). A multidimensional approach to individual differences in empathy. JSAS Catalog of Selected Documents in Psychology, 10, 85. Manuscript No. 2124.

Davis, M. H. (1996). Empathy: A social psychological approach. Boulder, CO: Westview Press.

Duan. C., \& Hill, C. (1996). The current state of empathy research. Journal of Counseling Psychology. 43. 261274.

Duryee. J., Brymer, M., \& Gold, K. (1996). The supervisory needs of neophyte psychotherapy interns. Journal of Clinical Psychology. 52. 663-671.

Epstein. M. (1995). Thoughts without a thinker. New York: Basic Books.

Epstein. R. M. (2003). Mindful practice in action (II): Cultivating habits of mind. Families, Systems \& Health. 21, 11-17.

Etringer, B. D., \& Hillerbrand, E. (1995). The transition from novice to expert counselor. Counselor Education and Supervision, 35, 4-18.

Feshbach. N. D. (1975). Empathy in children: Some theoretical and empirical considerations. The Counseling Psychologist, 5, 25-30.

Fong. M. L., Borders, L. D.. Ethington, C., \& Pitts, J. (1997). Becoming a counselor: A longitudinal study of student cognitive development. Counselor Education and Supervision, 37, 100-114.

Fulton. P. R. (2005). Mindfulness as clinical training. In C. K. Germer, R. D. Siegel, \& P. R. Fulton (Eds.), Mindfulness and psychotherapy (pp. 55-72). New York: Guilford Press.

Galantino, M. L., Baime, M., Maguire. M., Szapary. P. O., \& Farrar, J. T. (2005). Association of psychological and physiological measures of stress in healthcare professionals during an 8-week mindfulness meditation program: Mindfulness in practice. Stress and Health: Journal of the International Society for the Investigation of Stress. 21. 255-261.

Germer, C. K. (2005). Teaching mindfulness in therapy. In C. K. Germer, R. D. Siegel, \& P. R. Fulton (Eds.). Mindfulness and psychotherapy (pp. 113-129). New York: Guilford Press.

Gill, D. L. (2000). Psychological dynamics of sport and exercise (2nd ed.). Champaign, IL: Human Kinetics.

Goldstein. A. P., \& Michaels, G. Y. (1985). Empathy: Development, training, and consequences. Hillsdale, NJ: Eribaum. 
Gopher. D. (1993). The skill of attention control: Acquisition and execution of attention strategies. In D. E. Meyer \& S, Kornbluni (Eds.). Attention and performance XIV: Synergies in experimental psychology, artificial intelligences and cognitive neuroscience (pp. 299-322). Cambrido, MA: MIT Press.

Greason, P. B, (2006). Counselor Attention Scale. Winston-Salem. NC: Author.

Grossman, P., Niemann, L., Schmidt, S., \& Walach, H. (2004). Mindfulness-based stress reduction and health benefits: A meta-analysis. Journal of Psychosomatic Research, 57, 35-48.

Hoffman, M. L. (1975). Developmental synthesis of affect and cognition and its implications for altruistic motivation. Developmental Psychology, 11, 607-622.

Ivey, A. E., \& Ivey, M. B. (2003). Intentional interviewing and counseling (5th ed.). Pacific Grove, CA: Brooks/Cole.

Kabat-Zinn, J. (1994). Wherever you go, there you are: Mindfulness meditation in everyday life. New York: Hyperion.

Kabat-Zinn, J. (2003). Mindfulness-based interventions in context: Past, present, and future. Clinical Psychology: Science and Practice, 10, 144-156.

Keefe, T. (1976.) Empathy: The critical skill. Social Work. 21. 10-14.

Lambert, M. J., \& Barley, D. E. (2001). Research summary on the therapeutic relationship and psychotherapy outcome. Psychotherapy, 38. 357-361.

Larson, L. M., \& Daniels, J. A. (1998). Review of the counseling self-efficacy literature. The Counseling Psychologist, 26, 1 79-2 18.

Larson. L, M, Suzuki, L., Gillespie, K., Potenza, M. T., Toulouse, A. L., \& Bechtel, M. A. (1992). The development and validation of the Counseling Self-Estimate Inventory. Journal of Counseling Psychology, 39, 105-120.

Lazar, S. W. (2005). Mindfulness research. In C. K. Germer. R. D. Siegel. \& P. R. Fulton (Eds.), Mindfulness and psychotherapy (pp, 220-238). New York: Guilford Press.

Leach, M. M., Stoltenberg. C. D., McNeill, B. W., \& Eichenfield, G. A. (1997). Self-efficacy and counselor development: Testing the Integrated Developmental Model. Counselor Education and Supervision, 37, 115-124.

Leclercq. M. (2002). Theoretical aspects of the main components and functions of attention. In M. Leclercq \& P. Zimmerman (Eds.), Applied neuropsychology of attention (pp. 3-55). New York: Psychology Press,

Lent, R. W., Hackett. G., \& Brown, S. D. (1998). Extending social cognitive theory to counselor training: Problems and prospects, The Counseling Psychologist, 26, 295-306.

Lent, R. W. Hill. C, E., \& Hoffman, M. A. (2003). Development and validation of the Counselor Activity SelfEfficacy Scales. Journat of Counseling Psychology. 50, 97-108.

Mansfield. E. R., \& Helms. B. P. (1982). Detecting multicollinearity. The American Statistician, 36, 158-160.

Martin, J. R. (1997). Mindfulness: A proposed common factor. Journal of Psychotherapy Integration. 7, 291312.

Morgan, W. D., \& Morgan. S. T. (2005), Cultivating attention and empathy. In C. K. Germer. R. D. Siegel. \& P. R. Fulton (Eds.), Mindfulness and psychotherapy (pp. 73-90). New York: Guilford Press,

O’Byrne, K., Clark. R. E., \& Malakuti. R. (1997). Expert and novice performance: Implications for clinical training. Educational Psychology Review. 9, 321-332.

Orlinsky. D. E, Grawe. L., \& Parks, B. K. (1994). Process and outcome in psychotherapy-Noch einmal. In A. E. Bergin \& S. L. Garfield (Eds.), Handbook of psychotherapy and behavior change (4th ed., pp. 270-376). New York: Wiley.

Preacher. K. J., \& Hayes. A. F. (2008). Asymptotic and resampling strategies for assessing and comparing indirect effects in multiple mediator models. Behavior Research Methods, 40, 879-891.

Pulos. S., Elison, J., \& Lennon. R. (2004). The hierarchical structure of the Interpersonal Reactivity Index. Social Behavior and Personality, 32, 355-360.

Rogers, C. R. (1957). The necessary and sufficient conditions of therapeutic personality change. Journal of Consulting Psychology, 21, 95-103.

Rogers. C- R. (1975). Empathic: An unappreciated way of being. The Counseling Psychologist, 5, 2-10. 
Schure, M. B., Christopher. J., \& Christopher. S. (2008), Mind-body medicine and the art of self-care: Teaching mindfulness to counseling students through yoga, meditation, and Qigong. Journal of Counseling \& Development, 86. 47-56.

Segal, Z. V., Williams, J. M. G., \& Teasdale. J. D. (2002). Mindfulness-based cognitive therapy for depression. New York: Guilford Press.

Shapiro, S. L., Brown, K. W., \& Biegel, G. M. (2007). Teaching self-care to caregivers: Effects of mindfulnessbased stress reduction on the mental health of therapists in training. Training and Education in Professional Psychology, 1, 105-115.

Shapiro, S, L., Carlson, L. E., Arlin, D. A., \& Freedman. B. (2006), Mechanisms of mindfulness, Journal of Clinical Psychology, 62, 373-386.

Shapiro, S. L., Schwartz. G. E. R., \& Bonner. G. (1998). The effects of mindfulness-based stress reduction on medical and pre-medical students. Journal of Behavioral Medicine. 21, 581-599.

Skovholt, T. M., \& Ronnestad, M. H. (1992). Themes in therapist and counselor development. Journal of Counseling \& Development. 70, 503-315.

Stoltenberg, C. \& Delworth, U. (1987). Supervising counselors and therapists. San Francisco: Jossey-Bass.

Truax, C. B., \& Carkhuff, R. R. (1967). Toward effective counseling and psychotherapy: Training and practice. Chicago: Aldine.

Valentine. E. R., \& Sweet, P. L. G. (1999). Meditation and attention: A comparison of the effects of concentrative and mindfulness meditation on sustained attention. Mental Health, Religion \& Culture. 2 , 59-70.

Walsh, R., \& Shapiro, S. L. (2006), The meeting of meditative disciplines and Western psychology: A mutually enriching dialogue. American Psychologist, 61. 227-239.

Wampold, B. E. (2001), The great psychotherapy debate: Models, methods, and findings. Mahwah. NJ: Erlbaum.

Watson, J. C. (2001), Revisioning empathy: Theory, research, and practice. In D. Cain \& J. Seeman (Eds.). Handbook of research and practice in humanistic psychotherapy (pp. 445-472). Washington. DC: American Psychological Association.

Zimmerman, P., \& Leclercq. M. (2002), Neuropsychological aspects of attentional functions and disturbances. In M. Leclercq \& P. Zimmerman (Eds.). Applied neuropsychology of attention (pp. 56-85), New York: Psychology Press. 